\title{
Revascularisation difficulties in acute cardiac syndrome as debut of Takayasu arteritis
}

\author{
A. Riaño Ondiviela (D) · J. Alameda Serrano · A. Lukic Otanovic · J. R. Ruiz Arroyo
}

Accepted: 9 November 2020 / Published online: 30 November 2020

(c) The Author(s) 2020

A 44-year-old woman without cardiovascular risk factors presented with sudden oppressive chest pain. There were heart failure signs and a right carotid murmur; the left radial and brachial pulse were absent. Electrocardiography showed a 6-mm ST-segment elevation in V2-V6, suggesting anterior myocardial infarction. She was referred for emergent percutaneous coronary revascularisation and several insertion sites were tried to gain vascular access, but without success (Fig. 1). Percutaneous recanalisation and stent implantation in the right brachiocephalic branch were necessary to perform coronary angiography and angioplasty with drug-eluting stent implantation in a critical stenosis of the proximal part of the left descending coronary artery.

In this case, the clinical presentation, physical examination and angiographic findings suggested large-vessel vasculitis due to Takayasu disease [1-3]. Takayasu arteritis must be included in the differential diagnosis of acute coronary syndrome, especially in young women without cardiovascular risk factors [4].

Conflict of interest A. Riaño Ondiviela, J. Alameda Serrano, A. Lukic Otanovic and J.R. Ruiz Arroyo declare that they have no competing interests.
Open Access This article is licensed under a Creative Commons Attribution 4.0 International License, which permits use, sharing, adaptation, distribution and reproduction in any medium or format, as long as you give appropriate credit to the original author(s) and the source, provide a link to the Creative Commons licence, and indicate if changes were made. The images or other third party material in this article are included in the article's Creative Commons licence, unless indicated otherwise in a credit line to the material. If material is not included in the article's Creative Commons licence and your intended use is not permitted by statutory regulation or exceeds the permitted use, you will need to obtain permission directly from the copyright holder. To view a copy of this licence, visit http://creativecommons.org/licenses/by/4.0/.

\section{References}

1. Endo M, Tomizawa Y, Nishida H, et al. Angiographic findings and surgical treatments of coronary artery involvement in Takayasu arteritis. J Thorac Cardiovasc Surg. 2003;125:570-7.

2. Arend WP, Michel BA, Bloch DA, et al. The American College of Rheumatology 1990 criteria for the classification of Takayasu arteritis. Arthritis Rheum. 1990;3:1129-34.

3. Park MC, Lee SW, Park YB, Chung NS, Lee SK. Clinical characteristics and outcomes of Takayasu's arteritis: analysis of 108 patients using standardized criteria for diagnosis, activity assessment, and angiographic classification. Scand JRheumatol. 2005;34:284-92.

4. Toyofuku M, Goto Y, Matsumoto T, et al. Acute myocardial infarction in young Japanese women. J Cardiol. 1996;28:313-9.

\footnotetext{
A. Riaño Ondiviela $(\bowtie) \cdot J$. Alameda Serrano $\cdot$ A. Lukic Otanovic · J. R. Ruiz Arroyo

Cardiology Department, Hospital Clínico Universitario

Lozano Blesa, Zaragoza, Spain

arondiviela@gmail.com
} 
Fig. 1 Angiography showing occluded vascular access sites. a Right brachiocephalic artery. b Aberrant left brachiocephalic artery. c Right and d left common femoral artery
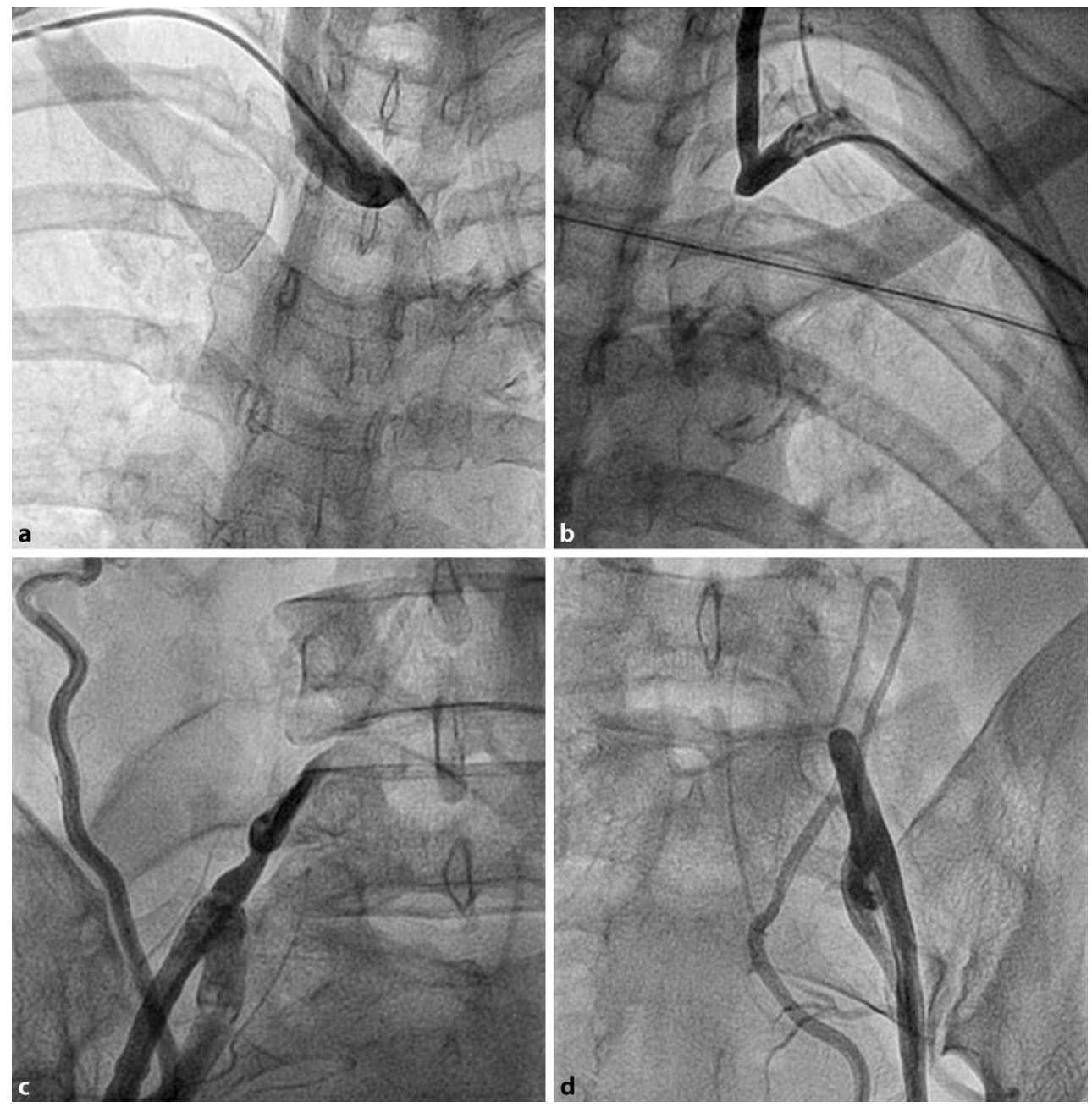